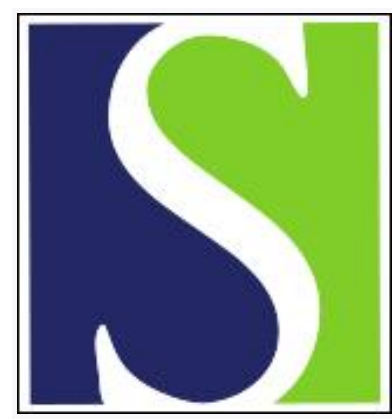

Scand J Work Environ Health 2002;28(6):418-428

https://doi.org/10.5271/sjweh.694

Issue date: Dec 2002

Time to pregnancy among partners of men exposed to di(2-ethylhexyl)phthalate

by Modigh CM, Bodin SLV, Lillienberg L, Dahlman-Höglund A, Åkesson $B$, Axelsson $G$

Affiliation: Department of Environmental Medicine, Göteborg University, PO Box 414, SE-405 30 Göteborg, Sweden.

Refers to the following text of the Journal: $1999 ; 25$ suppl 1:10-11

The following article refers to this text: 2003;29(6):444-451

Key terms: di(2-ethylhexyl)phthalate; fecundity; male; man; occupational exposure; partner; plasticizer; reproduction; time to pregnancy

This article in PubMed: www.ncbi.nlm.nih.gov/pubmed/12539802 


\title{
Time to pregnancy among partners of men exposed to di(2-ethylhexyl)phthalate
}

\author{
by Cecilia M Modigh, MD, ${ }^{1}$ S Lennart V Bodin, PhD, ${ }^{2}$ Linnéa Lillienberg, PhD, ${ }^{3}$ \\ Anna Dahlman-Höglund, PhD, ${ }^{3}$ Bengt Åkesson, PhD, ${ }^{4}$ Gösta Axelsson, $P h D^{1}$
}

\begin{abstract}
Modigh CM, Bodin SLV, Lillienberg L, Dahlman-Höglund A, Åkesson B, Axelsson G. Time to pregnancy among partners of men exposed to di(2-ethylhexyl)phthalate. Scand J Work Environ Health 2002;28(6):418-428.
\end{abstract}

Objectives This study assessed paternal occupational exposure to di(2-ethylhexyl)phthalate (DEHP) in association with reduced fertility.

Methods Men working in three plants with DEHP exposure were studied retrospectively. Male and female employees and their partners were invited to participate if they had reported a pregnancy or an attempt to achieve a pregnancy. Postal questionnaires and telephone interviews were used to collect additional data from the men and women, respectively. Information on time to pregnancy was eligible for 326 pregnancies fathered by 193 men. Male exposure to DEHP during every month of their time to pregnancy was classified into one of three exposure categories. The exposure ranged from $<0.1$ to $2.1 \mathrm{mg} / \mathrm{m}^{3}$. The fathers of only four pregnancies had DEHP exposure of $>0.5 \mathrm{mg} / \mathrm{m}^{3}$ during the time to pregnancy. The pregnancies of employed women with unexposed partners or pregnancies of employed men unexposed during the time to pregnancy formed the reference group.

Results The fecundability ratio for time to pregnancy was 1.07 [95\% confidence interval (95\% CI) $0.84-1.35$ ] for those with low exposure and 0.97 (95\% CI 0.70-1.33) for the highly exposed after adjustment for the father's age, mother's age, and length of recall. When the analyses were restricted to first pregnancy, the fecundability ratio was 1.13 (95\% CI 0.83-1.56) for low exposure and 1.02 (95\% CI 0.66-1.59) for high exposure.

Conclusions Time to pregnancy is not prolonged among couples with paternal exposure to DEHP at a mean exposure level of $<0.5 \mathrm{mg} / \mathrm{m}^{3}$.

Key terms fecundity, males, occupational exposure, plasticizer, reproduction.

In the last decade, increased attention has been paid to potentially harmful occupational exposures and their effects on the male reproductive system (1). It is possible for one or several stages of spermatogenesis to be involved and result in fewer or defective sperm cells.

The toxicity of di(2-ethylhexyl)phthalate (DEHP) has been extensively reviewed $(2,3)$. While many studies have shown reproductive damage in animals exposed to DEHP, the effects DEHP have not been investigated among humans, although the study by Fredricsson et al
(4) did find a decrease in sperm motility as a result of exposing human sperm cells to DEHP in vitro.

DEHP and its metabolite mono(2-exylhexyl)phthalate (MEHP) have been shown to cause different types of testicular injuries in developing and adult animals (510), mainly via oral exposure. One inhalation study of rats showed no adverse effects (11). DEHP is eliminated from the blood in only a few days, and there is no significant retention in the testicles (12). It is unclear whether DEHP-induced testicular damage is reversible,

1 Department of Environmental Medicine, Göteborg University, Göteborg, Sweden.

2 Statistical Unit, Örebro University Hospital, Örebro, and Department of Statistics, Örebro University, Örebro, Sweden.

3 Institute of Internal Medicine, Occupational Medicine, Göteborg University, Göteborg, Sweden.

4 Department of Occupational and Environmental Medicine, Lund University, Lund, Sweden.

Reprint requests to: Dr Gösta Axelsson, Department of Environmental Medicine, Göteborg University, Box 414, SE-405 30 Göteborg, Sweden. [E-mail: gosta.axelsson@envmed.gu.se] 
but it is probably a question of time and dose. Rats fed DEHP during the neonatal period, which was followed by an unexposed period, had normal fertility, and some, although not all, of the testicular injuries were reversible $(7,13)$. Since humans have a much smaller sperm reserve than rats, they are more likely to be sensitive to disturbances in the reproductive system, and therefore extrapolation from animal to man is complicated (14).

Time to pregnancy (ie, the number of menstrual cycles or months it takes a couple to achieve a pregnancy) can be used as a measure of fertility (15). Valid data on time to pregnancy can be derived retrospectively, even for as long as 20 years prior to the interview (16). Although most studies have dealt with female exposures, this method is also suitable for assessing the effects of male exposures (17).

The aim of this study was to investigate whether paternal occupational exposure to DEHP is associated with a prolonged time to pregnancy.

\section{Subjects and methods}

\section{Subjects}

Time to pregnancy was studied among couples in which the male partner had potentially been exposed to DEHP.
Data were collected between March 1997 and December 1998. All 962 employees from three plants either producing or using DEHP were approached with the use of a postal screening questionnaire. The screening aimed at identifying employed men and women who had become parents or who had unsuccessfully tried to become a parent between 1987 and the time of the interview. Altogether $770(80 \%)$ of the workers responded, and 284 satisfied the selection criteria and were invited to answer additional questions.

The reference group was formed from couples in which the male partner had not been occupationally exposed during time to pregnancy, either unexposed employed men or male partners of employed women.

\section{Data collection}

Data were collected in two steps, as described in figure 1 , beginning with the screening questionnaire. In the second step, a more-detailed questionnaire was sent to the men who met the criteria for reproductive history, and a telephone interview was made with the female employees who met the same criteria. In addition, the partners of the employees were contacted after approval by the employees, male partners by mail and female partners by telephone. One person (CM) conducted all the

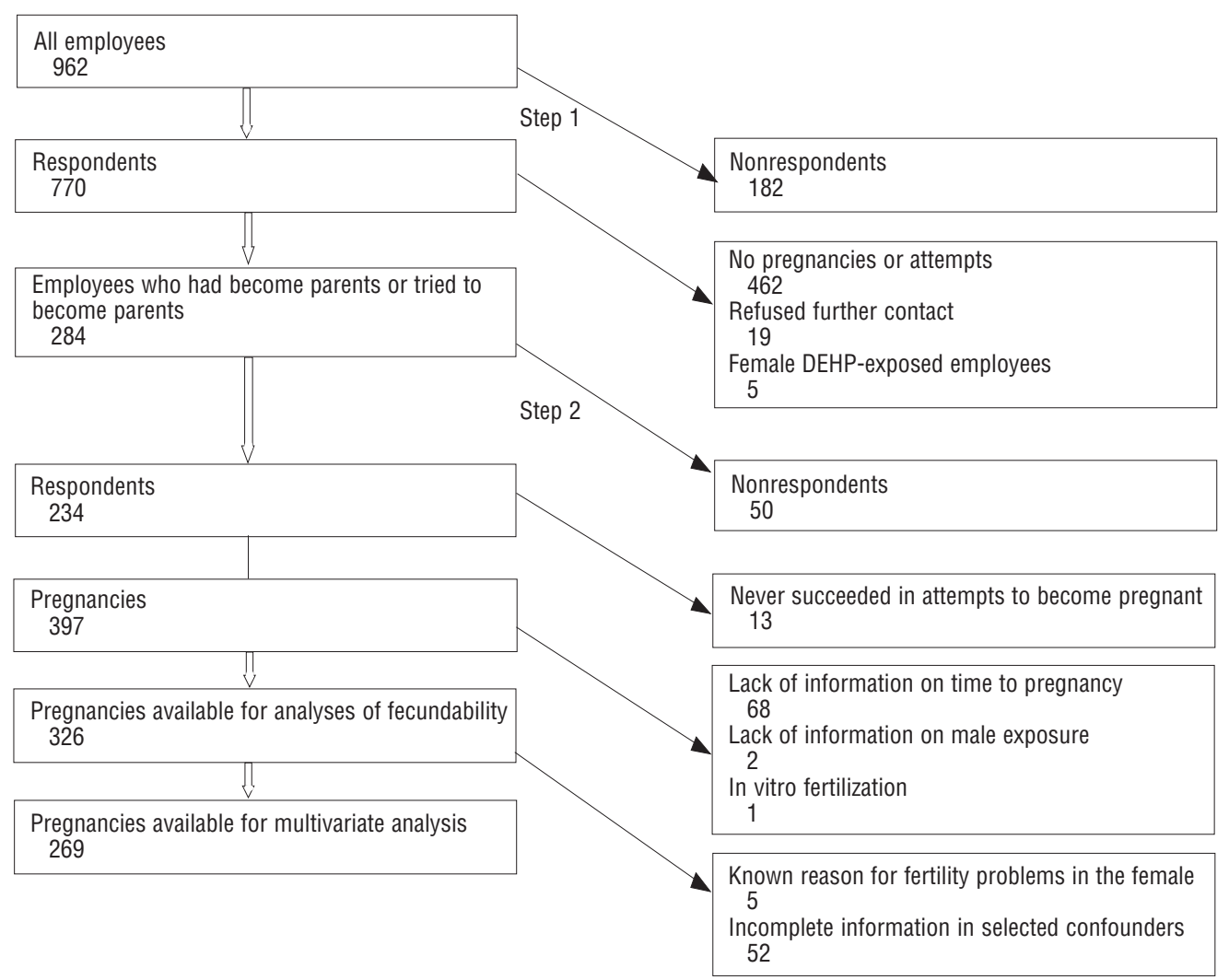

Figure 1. The two steps of the data collection-the response rates and reasons for exclusion before proceeding to the next step of data collection. [DEHP = di(2-ethylhexyl)phthalate] 
telephone interviews. Information on time to pregnancy was included for all pregnancies that ended in 1987 or later; several pregnancies could thus be attributed to each couple. Induced abortions were not included.

All potential subjects were informed that participation in the study was voluntary. The study was approved by the Regional Committee of Medical Research Ethics.

\section{Detailed questionnaire}

Both the men and women received questionnaires containing questions about pregnancies. Information concerning early pregnancy loss was collected only from the women, however. All the subjects were asked whether the pregnancy was "planned", "not planned", or "not planned but not avoided". Only when they reported the pregnancy as being "planned" or "not planned but not avoided" was additional information about the pregnancy collected.

The question on the main outcome, time to pregnancy, read as follows: "How many months did you have sexual intercourse without using any contraceptive method before you/she got pregnant". There were also questions about breast-feeding and the frequency of intercourse during the waiting time. To calculate the start of the pregnancy (or the end of time to pregnancy), the interviewer asked the women about the estimated date of birth, which almost all the women remembered. The start of the pregnancy was calculated by subtracting 38 weeks from the estimated date of birth. Information was also collected from both genders on potential confounders, such as life-style factors, health, and use of medication. Month was used as a proxy for menstrual cycle in the analysis.

\section{Participation and exclusion criteria}

A total of 227 couples participated, who together had 397 pregnancies. The overall response rate in this twostep procedure was estimated to be $66 \%$, on the assumption that the respondents in step 1 were representative of the whole cohort. The information on time to pregnancy or other data could originate from an employed woman or man or from a male or female partner. Among the 68 pregnancies lacking information on time to pregnancy, 43 were reported as not planned. For any question for which information was collected from both partners, data from the woman were chosen in the case of any disagreement.

The analyses of fecundability were based on information given for $89 \%$ of the pregnancies by the woman and for $11 \%$ by the man. The information from the women was either given in a telephone interview (79\%) or as she assisted her partner in completing the question- naire $(10 \%)$. One pregnancy that had been achieved with the assistance of in vitro fertilization was excluded. Two other pregnancies were excluded because of lack of information on male exposure to DEHP during the time of interest. Hence information on time to pregnancy, as well as male exposure, existed for 326 pregnancies.

Thirteen of the respondents had never or not yet succeeded in their attempt to become parents. Their unfinished periods of time to pregnancy were excluded from the analyses.

Subjects with previous fertility problems were included in the descriptive statistical summaries. However, in the additional multivariate analyses, the couples with a female partner who reported known fertility problems were excluded. In a supplementary analysis we also excluded all the couples that had reported any previous fertility problems. These problems were defined as one or several previous periods of $\geq 12$ months without pregnancy even though the couple had had sexual intercourse without using any contraceptives.

\section{Exposure assessment}

All the subjects were asked questions about their work location within the plants and about their worktasks from 1985 up to the time of the interview. The department staff supplemented information when needed.

Previous measurements of DEHP had been conducted using a variety of methods repeatedly in all three plants. For the evaluation of previous measurements and the assessment of current exposure, personal and stationary measurements were made at different work locations and for different tasks in the three plants. Method 5020 of the National Institute for Occupational Safety and Health (18) was used. Air samples were collected on glass fiber filters with an airflow of $1 \mathrm{l} / \mathrm{min}$, and the analyses were made with high-performance liquid chromatography and ultraviolet detection at 224 nanometers by an accredited laboratory. Simultaneous sampling with previously used methods was done in the production plant and in one of the processing plants.

\section{Exposure in the plant producing di(2-ethylhexyl)-phtha-} late. Workers in the production plant were process operators, maintenance workers (electricians, mechanics and welders), and laboratory personnel. The process operators work 2 to 3 months a year in the DEHP production area, their main tasks being supervision of the process from the control room and sample collection during the process. Less frequently, about twice a month, a close-meshed filter is cleaned, involving open handling of DEHP remnants with a temperature of about $100^{\circ} \mathrm{C}$. Exposure can also occur when the coarse-meshed filter is changed (4 times a year) or when the process equipment is cleaned during the yearly process stop. Peak 
exposure before 1995 was probably higher because of changes in the handling of the filters. Mechanics and electricians are exposed to peak exposures during repair work at the plant. About 10 times a year the plant conducts stationary measurements in the processing area at three locations with a nonselective method (gas-washing bottle in 2-ethyl hexanol).

Personal and stationary samples of current exposure in the production plant showed very low levels. Process operators who spent most of their workhours in the control room had DEHP exposures below or close to the detection limit $\left(0.01 \mathrm{mg} / \mathrm{m}^{3}, \mathrm{~N}=8\right)$.

Laboratory staff had DEHP exposures below the detection limit $(\mathrm{N}=2)$. Mechanics doing repair work had a mean exposure of $0.1 \mathrm{mg} / \mathrm{m}^{3}$ during a 4-hour period in the DEHP production area $(\mathrm{N}=3)$. Stationary measurements in the control room and the laboratory showed values below the detection limit $(\mathrm{N}=8)$. In the process area stationary measurements showed values between 0.02 and $0.04 \mathrm{mg} / \mathrm{m}^{3}(\mathrm{~N}=58)$. The nonselective method used in the production plant showed 2 to 40 times higher values $\left(0.05-0.75 \mathrm{mg} / \mathrm{m}^{3}, \mathrm{~N}=6\right)$, probably due to an unintentional inclusion of monoesters. From this comparison and old results of DEHP measurements, it was concluded that only current measurements could be used in the estimation of exposure, together with information on worktasks during the time periods of interest. Even if the mechanics had been exposed to around or above $0.1 \mathrm{mg} / \mathrm{m}^{3}$ during maintenance work their weekly mean exposure to DEHP was estimated to be below $0.1 \mathrm{mg} / \mathrm{m}^{3}$.

Exposure in the plants processing polyvinyl chloride. In one of the processing plants, polyvinyl chloride (PVC) floor sheeting was manufactured using primarily DEHP and aliphatic hydrocarbons as plasticizers. The maximum temperature in the calenders was $180^{\circ} \mathrm{C}$. The speed of the calenders had continuously increased, while the local exhaust devices above the calenders had been improved. There was a concomitant exposure to $\mathrm{N}$-metyl2-pyrrolidone $\left(0.1-0.2 \mathrm{mg} / \mathrm{m}^{3}\right)$ that was less than $10^{-3}$ of the NOAEL (no observed adverse effect level) of reproduction toxicity in rodents (19). In the other processing plant, thin film was calendered from PVC, with DEHP as the main plasticizer. The workers in the plants were calender or machine operators, machine attendants, maintenance workers, product controllers, and mixing workers. In both processing plants there was an intermittent exposure to the thermodegradation products of PVC, mainly hydrogen chloride. The exposure did not parallel the exposures to DEHP. The exposure to vinyl chloride was $<0.1 \mathrm{mg} / \mathrm{m}^{3}$.

In the two processing plants, about 250 personal exposure measurements of DEHP had been made between 1982 and 1998; these measurements could be used in the assessment of exposure. Appendix 1 shows the exposure groups as defined by the task of the workers and the location of the calender. The calender operators were the most highly exposed, followed by the machine attendants. The exposure differed considerably between different plants and calenders. Within several of the task groups the exposure to DEHP varied considerably, the geometric standard deviations ranging from 1.04 to 4.91. The groups were tested for normality with the use of Shapiro-Wilks statistics. As only a few groups were normally distributed, the data were log-transformed. The new distributions showed adequately normal distributions, indicating that the exposure followed a log-normal distribution.

In appendix 2, the differences between the exposure concentrations measured during different years were tested by one-way analyses of variance. In six out of the seven analyses, the between-worker variance was larger than the between-year variance $(\mathrm{F}>1)$. In six out of the seven analyses, the differences in exposure between the years of measurement did not significantly differ. The highest levels were usually found among the most recent measurements. For a few calenders without any measurements, the exposures for different task groups were estimated from similar production with the differences in production volumes, general and exhaust ventilation, and the like taken into consideration.

The current mean exposure during whole-shift measurements ranged from $<0.1$ to $2.1 \mathrm{mg} / \mathrm{m}^{3}$.

Classification. Estimations of the mean exposure were used to create five exposure categories (table 1). In the final grouping, it was necessary to merge the three most highly exposed groups into one, as there were few subjects in these groups (total 44). For that reason, the mean exposure of the highest class of exposure had a wide range-from 0.1 to $1.9 \mathrm{mg} / \mathrm{m}^{3}$. To investigate further the presence of increased risk in the groups with the highest exposures, we combined the original groups IV and $\mathrm{V}$, and group III was kept separate in an additional analysis. DEHP exposure was recorded for each month during which pregnancy was attempted. When there was information on time to pregnancy from both partners in a couple, data on time to pregnancy given by the woman were used in the analyses. In these cases, the monthly male exposure information was adjusted, if necessary, to correspond with the woman's months of time to pregnancy. Partners of responding employees who were not respondents themselves were classified as unexposed to DEHP, provided that they had never worked at any of the plants. There may have been a potential hazardous effect of DEHP in different stages of spermatogenesis. Since spermatogenesis takes about 70 days, a decline in fertility may occur after exposure taking place 3 months prior to the specific month of time to pregnancy. To take 
Table 1. Groups according to exposure to di(2-ethylhexyl)phthalate (DEHP). The number of pregnancies in each exposure group was based on the exposure of the men during the first month of attempted pregnancy. The same occupation occurs in different subgroups of exposure since they represent different calenders and machines or year of exposure.

\begin{tabular}{|c|c|c|c|c|}
\hline \multirow{2}{*}{$\begin{array}{l}\text { Exposure } \\
\text { group }\end{array}$} & \multirow{2}{*}{$\begin{array}{l}\text { DEHP } \\
\text { level }\end{array}$} & \multicolumn{3}{|c|}{ Occupation and location } \\
\hline & & Production plant & Processing plant I & Processing plant II \\
\hline $\begin{array}{l}\text { None (group I) } \\
(\mathrm{N}=182)\end{array}$ & $0 \mathrm{mg} / \mathrm{m}^{3}$ & $\begin{array}{l}\text { Operators (unexposed during time to pregnancy) } \\
\text { Office staff } \\
\text { Partners of employed women }\end{array}$ & & \\
\hline $\begin{array}{l}\text { "Low" (group II) } \\
(\mathrm{N}=100)\end{array}$ & $<0.1 \mathrm{mg} / \mathrm{m}^{3}$ & $\begin{array}{l}\text { Operators (if exposed) } \\
\text { Maintenance workers } \\
\text { Laboratory staff }\end{array}$ & $\begin{array}{l}\text { Machine attendants (II) } \\
\text { Product control (II) } \\
\text { Laboratory staff }\end{array}$ & $\begin{array}{l}\text { Machine attendants II) } \\
\text { Laboratory staff }\end{array}$ \\
\hline \multicolumn{5}{|l|}{ "High" } \\
\hline $\begin{array}{l}\text { Group III } \\
(N=25)\end{array}$ & $0.1-<0.2 \mathrm{mg} / \mathrm{m}^{3}$ & & $\begin{array}{l}\text { Machine attendants (III) } \\
\text { Product control (III) } \\
\text { Mixers }\end{array}$ & $\begin{array}{l}\text { Calender operators (III) } \\
\text { Maintenance workers (III) }\end{array}$ \\
\hline $\begin{array}{l}\text { Group IV } \\
(\mathrm{N}=15)\end{array}$ & $0.2-<0.5 \mathrm{mg} / \mathrm{m}^{3}$ & & $\begin{array}{l}\text { Machine attendants (IV) } \\
\text { Product control (IV) }\end{array}$ & $\begin{array}{l}\text { Machine attendants (IV) } \\
\text { Calender operators (IV) }\end{array}$ \\
\hline $\begin{array}{l}\text { Group V } \\
(\mathrm{N}=4)\end{array}$ & $\geq 0.5 \mathrm{mg} / \mathrm{m}^{3}$ & & Calender operators (V) & Calender operators (V) \\
\hline
\end{tabular}

the time lag into account, we recorded the male exposure to DEHP 1, 2, and 3 months prior to every corresponding month of attempted pregnancy.

\section{Statistical analysis}

Time to pregnancy in months was analyzed in the first descriptive phase without truncation at the 12-month limit. Medians therefore refer to actual observed time. In the subsequent analyses with extended regression models, censoring at the 12-month limit was introduced (ie, right-hand censoring was introduced).

The outcome parameter was the fecundability ratio between exposed and unexposed months. The fecundability ratio was calculated using a discrete time analogue of the Cox proportional hazards model (20). The unit of analysis in this model is the month, which gives the possibility of including time-varying exposure, in particular with respect to the monthly exposure to DEHP. All the estimates were conditional on pregnancy (ie, only couples that achieved a pregnancy were included in the study) (21). The model was fitted using a binomial regression model [ie, a generalized linear model with a logarithmic link function as suggested by Wacholder (22)]. Fecundability ratio estimates below unity indicate subfertility. Ninety-five percent confidence intervals (95\% CI) were calculated by means of standard errors of the parameters included. Our analytical models were equivalent to regression models for the analysis of relative risks (RR), but the interpretation of the outcome parameter, the fecundability ratio, was reversed with respect to risk (ie, a low fecundability ratio indicated the presence of a risk factor).
The analyses were based on pregnancies and months with complete data for the male exposure variable and for the finally selected confounders.

Potential confounders were considered for inclusion in the final model if their effect on male exposure led to changes in the estimated fecundability ratio for DEHP exposure with more than approximately $10 \%$ in a model with the confounder and DEHP exposure included compared with the crude estimate of the fecundability ratio for DEHP (ie, only DEHP exposure included). Since our first analysis without any confounders indicated high fecundability ratios for exposure, we watched especially for confounders whose exclusion from the model could have caused these enhanced crude estimates. Month order was always included in the analytical models (ie, also for those models that gave us the estimates of the crude fecundability ratio).

Multiple pregnancies were included for each pertinent couple in the analysis. In an attempt to analyze a possible effect of the dependency implicit in a simultaneous analysis of several pregnancies per couple, we did an additional analysis in which only the first recorded pregnancy of each couple was included.

\section{Results}

Table 1 shows the distribution of exposure in three categories. For $55 \%$ of the pregnancies, the pregnancies were fathered by men who were unexposed during the time to pregnancy, while $31 \%$ were exposed to a low level of DEHP $\left(<0.1 \mathrm{mg} / \mathrm{m}^{3}\right)$ and $13 \%$ had a "high" exposure level $\left(\geq 0.1 \mathrm{mg} / \mathrm{m}^{3}\right)$. 
In all, $24 \%$ of the partners of unexposed men became pregnant in the first month as compared with $30 \%$ and $43 \%$ in the low and high exposure groups, respectively. The median time to pregnancy for the three groups was 3.0, 2.25 and 2.0 months, respectively. The distributions of different parent characteristics that may be related to time to pregnancy and to the father's exposure to DEHP are presented in tables 2 and 3. Those who had the highest exposure to DEHP where younger, had a lower educational level, smoked more, and more often worked nights than those in the other exposure groups. The age and educational level of the mother were also statistically associated with the DEHP exposure of the father. We decided to include the father's age, mother's age, and start of time to pregnancy (as proxy for length of recall) as covariates in the model since these three variables had an estimated effect on the adjusted fecundability ratio for male exposure that was greater than or equal to our criterion for inclusion, a $10 \%$ change. The crude and adjusted fecundability ratios for exposure to DEHP in separate menstrual cycles are given in table 4. All told, 269, obtained from 153 couples, of the

Table 2. Characteristics of the 192 mothers of the 326 pregnancies related to time to pregnancy and stratified according to the fathers' exposure to di(2-ethylhexyl)phthalate (DEHP).

\begin{tabular}{|c|c|c|c|c|c|c|c|}
\hline \multirow[t]{2}{*}{ Characteristic } & \multirow{2}{*}{$\begin{array}{l}\text { Time to pregnancy } \\
\text { (median in months) }\end{array}$} & \multicolumn{2}{|c|}{ No DEHP exposure } & \multicolumn{2}{|c|}{ Low DEHP exposure } & \multicolumn{2}{|c|}{ High DEHP exposure } \\
\hline & & $\mathrm{N}$ & $\%{ }^{a}$ & $\mathrm{~N}$ & $\%{ }^{a}$ & $\mathrm{~N}$ & $\%^{a}$ \\
\hline \multicolumn{8}{|l|}{ Age } \\
\hline$<29$ years & 2.5 & 97 & 59.5 & 61 & 62.9 & 32 & 72.7 \\
\hline $30-34$ years & 2.5 & 46 & 28.2 & 31 & 32.0 & 9 & 20.5 \\
\hline$>34$ years & 3.5 & 20 & 12.3 & 5 & 5.2 & 3 & 6.8 \\
\hline \multicolumn{8}{|l|}{ Smoking } \\
\hline No cigarettes/day & 3.0 & 102 & 65.4 & 58 & 69.0 & 23 & 62.2 \\
\hline 1-19 cigarettes/day & 3.0 & 42 & 26.9 & 17 & 20.2 & 13 & 35.1 \\
\hline$>19$ cigarettes/day & 2.2 & 12 & 7.7 & 9 & 10.7 & 1 & 2.7 \\
\hline \multicolumn{8}{|l|}{ Coffee consumption } \\
\hline$<1$ cup/day & 2.5 & 41 & 26.3 & 18 & 21.4 & 9 & 24.3 \\
\hline $1-3$ cups/day & 3.0 & 65 & 41.7 & 29 & 34.5 & 9 & 24.3 \\
\hline$\geq 4$ cups/day & 3.0 & 50 & 32.1 & 37 & 44.0 & 19 & 51.4 \\
\hline \multicolumn{8}{|l|}{ Education } \\
\hline Comprehensive school & 4.0 & 12 & 7.7 & 11 & 13.1 & 4 & 10.8 \\
\hline Upper secondary school & 3.0 & 97 & 62.2 & 55 & 65.5 & 30 & 81.1 \\
\hline University & 2.5 & 47 & 30.1 & 18 & 21.4 & 3 & 8.1 \\
\hline \multicolumn{8}{|l|}{ Maternal exposure to DEHP } \\
\hline Unexposed & 3.0 & 169 & 92.9 & 100 & 100.0 & 42 & 95.5 \\
\hline$<0.1 \mathrm{mg} / \mathrm{m}^{3}$ & 4.2 & 9 & 4.9 & 0 & 0 & 1 & 2.3 \\
\hline$\geq 0.1 \mathrm{mg} / \mathrm{m}^{3}$ & 2.0 & 4 & 2.2 & 0 & 0 & 1 & 2.3 \\
\hline \multicolumn{8}{|l|}{ Salpingitis } \\
\hline No & 3.0 & 144 & 92.9 & 77 & 91.7 & 34 & 91.9 \\
\hline Yes & 3.0 & 11 & 7.1 & 7 & 8.3 & 3 & 8.1 \\
\hline \multicolumn{8}{|c|}{ Recent hormonal contraceptive use } \\
\hline No & 2.5 & 98 & 62.0 & 65 & 67.0 & 30 & 68.2 \\
\hline Yes & 3.0 & 60 & 38.0 & 32 & 33.0 & 14 & 31.8 \\
\hline \multicolumn{8}{|l|}{ Regularity of menstrual cycles } \\
\hline Yes & 3.0 & 141 & 90.4 & 77 & 91.7 & 35 & 94.6 \\
\hline No & 3.5 & 15 & 9.6 & 7 & 8.3 & 2 & 5.4 \\
\hline \multicolumn{8}{|l|}{ Parity } \\
\hline 1 & 3.0 & 71 & 39.0 & 26 & 26.0 & 14 & 31.8 \\
\hline 2 & 2.5 & 67 & 36.8 & 38 & 38.0 & 18 & 40.9 \\
\hline$\geq 3$ & 3.0 & 44 & 24.2 & 36 & 36.0 & 12 & 27.3 \\
\hline \multicolumn{8}{|l|}{ Frequency of intercourse } \\
\hline$>1 /$ week & 3.0 & 102 & 62.6 & 62 & 68.9 & 22 & 57.9 \\
\hline$\leq 1 /$ week & 2.0 & 61 & 37.4 & 28 & 31.1 & 16 & 42.1 \\
\hline \multicolumn{8}{|l|}{ Previous fertility problems } \\
\hline No & 2.0 & 143 & 78.6 & 83 & 83.0 & 34 & 77.3 \\
\hline Yes & 10.0 & 39 & 21.4 & 17 & 17.0 & 10 & 22.7 \\
\hline \multicolumn{8}{|l|}{ Outcome of pregnancy } \\
\hline Live birth & 3.0 & 167 & 92.3 & 92 & 92.0 & 41 & 95.3 \\
\hline Other & 3.0 & 14 & 7.7 & 8 & 8.0 & 2 & 4.7 \\
\hline
\end{tabular}

a Percentage of those who responded to the question. 
Table 3. Characteristics of the 193 fathers of the 326 pregnancies related to time to pregnancy and stratified according to the father's exposure to di(2-ethylhexyl)-phthalate (DEHP).

\begin{tabular}{|c|c|c|c|c|c|c|c|}
\hline \multirow[t]{2}{*}{ Characteristic } & \multirow{2}{*}{$\begin{array}{l}\text { Time to pregnancy } \\
\text { (median in months) }\end{array}$} & \multicolumn{2}{|c|}{ No DEHP exposure } & \multicolumn{2}{|c|}{ Low DEHP exposure } & \multicolumn{2}{|c|}{ High DEHP exposure } \\
\hline & & $\mathrm{N}$ & $\%^{a}$ & $\mathrm{~N}$ & $\%^{a}$ & $\mathrm{~N}$ & $\%{ }^{a}$ \\
\hline \multicolumn{8}{|l|}{ Father's age } \\
\hline$<29$ years & 2.5 & 59 & 38.1 & 43 & 43.0 & 27 & 61.4 \\
\hline $30-34$ years & 2.0 & 46 & 29.7 & 24 & 24.0 & 13 & 29.5 \\
\hline$>34$ years & 4.0 & 50 & 32.3 & 33 & 33.0 & 4 & 9.1 \\
\hline \multicolumn{8}{|l|}{ Father's smoking (cig/day) } \\
\hline No cigarettes/day & 2.2 & 107 & 73.3 & 70 & 78.7 & 23 & 57.5 \\
\hline $1-19$ cigarettes/day & 4.0 & 27 & 18.5 & 14 & 15.7 & 13 & 32.5 \\
\hline >19 cigarettes/day & 3.0 & 12 & 8.2 & 5 & 5.6 & 4 & 10.0 \\
\hline \multicolumn{8}{|l|}{ Male education } \\
\hline Comprehensive school & 4.5 & 16 & 10.5 & 10 & 10.8 & 8 & 20.5 \\
\hline Upper secondary school & 3.0 & 96 & 62.7 & 69 & 74.2 & 31 & 79.5 \\
\hline University & 2.0 & 41 & 26.8 & 14 & 15.1 & - & . \\
\hline \multicolumn{8}{|l|}{ Father working night time } \\
\hline No & 2.5 & 104 & 68.4 & 38 & 38.0 & 2 & 4.5 \\
\hline Yes & 3.0 & 48 & 31.6 & 62 & 62.0 & 42 & 95.5 \\
\hline \multicolumn{8}{|l|}{ Cryptorchism } \\
\hline No & 3.0 & 148 & 97.4 & 97 & 100.0 & 38 & 95.0 \\
\hline Yes & 5.0 & 4 & 2.6 & - & $\cdot$ & 2 & 5.0 \\
\hline \multicolumn{8}{|l|}{ Start year of TTP } \\
\hline 1981-1988 & 3.0 & 68 & 37.4 & 28 & 28.0 & 9 & 20.5 \\
\hline 1989-1992 & 3.0 & 80 & 44.0 & 36 & 36.0 & 16 & 36.4 \\
\hline $1993-1997$ & 2.0 & 34 & 18.7 & 36 & 36.0 & 19 & 43.2 \\
\hline
\end{tabular}

a Percentage of those who responded to the question.

analyzed pregnancies had complete data-resulting in 1036 months of time to pregnancy. There were small differences in time to pregnancy between the three exposure groups. The unadjusted fecundability ratios for time to pregnancy were 1.08 (95\% CI $0.86-1.36$ ) for months in which the exposure was low and 1.04 (95\% CI 0.76-1.43) for months in which exposure was high. After adjustment, the fecundability ratios were 1.07 (95\% CI 0.84-1.35) and 0.97 (95\% CI 0.70-1.33), respectively. To consider the time lag of sperm maturity, we also recorded the male exposure to DEHP 1,2 , and 3 months prior to every corresponding month of attempted pregnancy. The crude and adjusted fecundability ratios were approximately the same (table 4) when these lagged exposures were used instead of current (not lagged) exposure. This material showed little fluctuation in exposure, and the lack of fluctuation explains the consistency of the calculations.

Restricting the analysis to the first recorded pregnancy resulted in 630 months of time to pregnancy for 153 pregnancies of 153 couples. The fecundability ratios were essentially the same as those reported for all available pregnancies. The adjusted fecundability ratio for current exposure was 1.36 (95\% CI 0.83-1.56) for low exposure and 1.02 (95\% CI 0.66-1.59) for high exposure.
As stated earlier, because of the small number of pregnancies among the couples belonging to the group with high exposure, the three groups with the highest exposure were merged into one in the preceding analyses. To investigate further the presence of increased risk (lower fecundability ratio) in the subgroups with the highest exposures, we combined the original groups IV and V and kept group III separate (table 1). The adjusted fecundability ratio for group III was 0.95 (95\% CI $0.63-$ 1.42 ), and for groups IV and V it was 0.99 (95\% CI $0.63-1.55)$ when a comparison was made with the reference group.

Women who were exposed in the DEHP processing plants during the time to pregnancy were included in the preceding analyses. When these 13 pregnancies were excluded and the analysis was confined to 979 months of time to pregnancy, the fecundability ratios for male exposure were about the same, namely, 1.03 (95\% CI $0.81-1.32)$ and 1.01 (95\% CI 0.73-1.41). Similarly, an additional number of 55 pregnancies among the couples that reported any known fertility problems were excluded, resulting in 731 analyzed months, and the re-analysis revealed no important changes in the fecundability ratio, 1.06 (95\% CI $0.85-1.34)$ for the low exposure group and 1.28 (95\% CI 0.94-1.74) for those with high exposure. 
Table 4. Crude and adjusted fecundability ratios (FR) for male exposure to di(2-ethylhexyl)phthalate (DEHP), with or without adjustment for the time lag of sperm maturity. ${ }^{a}$

\begin{tabular}{|c|c|c|c|c|}
\hline Male exposure to DEHP & Crude FR & $95 \% \mathrm{Cl}$ crude & Adjusted FR & $95 \% \mathrm{Cl}$ adjusted \\
\hline \multicolumn{5}{|l|}{ Current cycle } \\
\hline Unexposed (n=508) & 1.0 & .. & 1.0 & .. \\
\hline Low exposure $(\mathrm{N}=376)$ & 1.08 & $0.86-1.36$ & 1.07 & $0.84-1.35$ \\
\hline High exposure $(\mathrm{N}=152)$ & 1.04 & $0.76-1.43$ & 0.97 & $0.70-1.33$ \\
\hline \multicolumn{5}{|l|}{ Lagged one cycle } \\
\hline Unexposed $(\mathrm{N}=513)$ & 1.0 & .. & 1.0 &.. \\
\hline Low exposure (N=368) & 1.11 & $0.89-1.40$ & 1.10 & $0.87-1.39$ \\
\hline High exposure $(\mathrm{N}=155)$ & 1.00 & $0.73-1.38$ & 0.93 & $0.67-1.29$ \\
\hline \multicolumn{5}{|l|}{ Lagged two cycles } \\
\hline Unexposed $(\mathrm{N}=517)$ & 1.0 & .. & 1.0 &.. \\
\hline Low exposure $(\mathrm{N}=360)$ & 1.10 & $0.88-1.39$ & 1.09 & $0.86-1.38$ \\
\hline High exposure $(\mathrm{N}=159)$ & 1.06 & $0.78-1.44$ & 0.97 & $0.71-1.34$ \\
\hline \multicolumn{5}{|l|}{ Three cycles } \\
\hline Unexposed $(\mathrm{N}=520)$ & 1.0 & .. & 1.0 & .. \\
\hline Low exposure (N=356) & 1.10 & $0.87-1.38$ & 1.09 & $0.86-1.38$ \\
\hline High exposure $(\mathrm{N}=160)$ & 1.08 & $0.80-1.46$ & 0.99 & $0.72-1.35$ \\
\hline
\end{tabular}

a Multivariate analysis of 1036 months for 269 pregnancies of 153 men, adjusted for paternal age, mother's age, and length of recall, all referring to the beginning of time to pregnancy.

\section{Discussion}

There was no support for an association between DEHP exposure and a prolonged time to pregnancy. The median time to pregnancy in the three exposure groups was between 2 and 3 months, which are in the normal range of comparable studies $(17,23,24)$. The number of men highly exposed during time to pregnancy was relatively small. Thus the three highest classes of exposure were merged into one, the result being a wide range of mean exposure for this group. For this reason it is not possible to draw the conclusion that men with the highest exposure run no risk of a decrease in fecundability. Still, when the two groups with the highest exposure were merged, rather than the three most highly exposed groups, the results did not change, although only in 4 of the 19 pregnancies did the mean exposure exceed $0.5 \mathrm{mg} / \mathrm{m}^{3}$. In some of the pregnancies, exposure during time to pregnancy may have been higher because of temporary problems with the production processes, resulting in high peak exposures. The opposite was not likely since the current measurements were conducted under reasonably normal conditions. Given that the recall of time to pregnancy was correct, misclassification of exposed versus unexposed time to pregnancy was considered to be limited, since several sources of information were used to record worktasks and locations.

To limit further the risk and consequences of a misclassification of exposure, it is important to take into account if and when the exposure occurred during spermatogenesis, when the effect is reversible. In our study, the fluctuation in exposure was rather limited, and thus lagging data did not change the results substantially.
This study focused on adult men with occupational exposures to DEHP. This setting was chosen to allow an accurate exposure assessment and to select a relatively highly exposed group of men. However, adverse effects caused exclusively by pre- or perinatal exposure of the man would not be detected with this design.

Zielhuis et al (25) showed that there is a high validity and reliability for retrospective fecundability data collected with both telephone interviews and postal questionnaires. Baird et al (26) concluded that information from a short postal questionnaire agreed well with that of a detailed telephone interview, although there was a loss in the power of detecting weak exposures. Joffe et al (16) demonstrated a high validity for selfcompletion questionnaires, as well as for personal interviews for long-term recalls. For 126 of the pregnancies in our study, the women gave the information on time to pregnancy twice, in the interview and when assisting their partners in completing the questionnaire. When comparing these data, we observed no systematic differences, the mean difference in reported time to pregnancy being 0.91 ( $\mathrm{P}=0.88$, paired t-test).

Eleven percent of the time to pregnancy data was given by the men only. Coughlin et al (27) showed that male recall of time to pregnancy agreed well with information given by the female partner. Since the distribution of the source of information was about the same in the three categories of exposure, it is unlikely that the results would have been influenced.

The analyses of time to pregnancy in relation to DEHP exposure were based on 269 pregnancies among 153 couples. In 139 of these pregnancies, the father was exposed at the time of the first month of time to 
pregnancy. For the detection of a $50 \%$ decrease in fecundability with a power of $80 \%$ at the $5 \%$ level of significance, 55 exposed and 55 unexposed pregnancies would be required (26). These calculations do not consider any confounding or misclassification, the implication being that the number of pregnancies should be larger to preserve a power of $80 \%$. Moreover, dependence between pregnancies among the same parents in the study could have resulted in a slightly underestimated confidence interval and a loss of power (28). However, since the number of pregnancies was three times as many as suggested and the confidence intervals for the estimates of the fecundability ratio were rather narrow, the power should be reasonable.

Working women are considered to include a higher proportion of subfertile women than women outside the workforce, the "infertile workers effect" (29). Women recruited as partners of male workers could be outside the workforce, unlike the women recruited from the plants. Furthermore, women employed at the plants were more likely to have been in the reference group than those who were recruited as partners of male employees, and therefore bias could have resulted. In Sweden, however, the legislation concerning maternity leave is generous; consequently most women leave their jobs only temporarily when they have children. In our study, we included women on maternity leave. To control further for this possible bias, we also analyzed fecundability ratios after excluding pregnancies of employed women from the reference group ( 60 pregnancies). The fecundability ratio differed only slightly, with no change in the low exposure group, and was 1.05 instead of 0.97 for the high exposure group.

Differential misclassification caused by the interviewer was not probable since data on time to pregnancy and exposure were collected independently with only a few exceptions.

Persons who were exposed to DEHP and also had a long time to pregnancy may have been more likely to participate in our study than those who were unexposed, and those who reported a long time to pregnancy may also have tended to report handling DEHP to a greater extent. However, the subjects who had been exposed were not aware of how they were to be classified. The men had little knowledge of what period of time in which we were interested, and the classification was furthermore mainly based on other sources than information from the man. Knowledge of what is a normal length of time to pregnancy was also limited, a fact that further diminishes both the risk of selection and recall bias. However, sterility or a very long time to pregnancy would have been recognized and could therefore have influenced the willingness to respond. The proportion of employees who reported an unsuccessful or not yet successful attempt to achieve a pregnancy was $6 \%$, a level consistent with that of the general population (30). Periods of time to pregnancy that did not result in pregnancy were not included in the analyses.

Since we did not recruit persons who had worked at the plants during the same time as the recorded pregnancies, persons with a more distant pregnancy were more likely to be unexposed than those with a recent pregnancy. The median onset of time to pregnancy was 1989 for the unexposed group and 1991 and 1992 for the low and high exposure groups, respectively. In addition, previous and current measurements showed that exposure had been somewhat higher in the last few years. By adjusting for year of time to pregnancy, we think that this potential bias was avoided.

In summary, our results do not support an association between paternal exposure to DEHP during time to pregnancy and a prolonged time to pregnancy at a mean exposure level of $<0.5 \mathrm{mg} / \mathrm{m}^{3}$.

\section{Acknowledgments}

Funds from the Swedish Environment Protection Agency and the Swedish Work Environment Fund supported this study.

The authors gratefully acknowledge the help of Anna-Lena Rykfors, Johnny Olsson, Ingmar Andersson, Inger Hjalmarsson, and Eva Ekholm at the participating plants.

\section{References}

1. Tas S, Lauwerys R, Lison D. Occupational hazards for the male reproductive system. Crit Rev Toxicol 1996;26:261-307.

2. Agency for Toxic Substances and Disease Registry (ATSDR). Toxicological profile for di (2-ethylhexyl)phtalate (update) TP-92/05. Atlanta (GA): US Department of Health and Human Services, 1993.

3. Canadian Environmental Protection Act (CEPA). Priority substance list assessment report: bis(2-ethylhexyl) phthalate. Quebec: Canadian Communication Group, 1994: 44 p. (ISBN 0-662-22031-5)

4. Fredricsson B, Möller L, Pousette A, Westerholm R. Human sperm motility is affected by plasticizers and diesel particle extracts. Pharmacol Toxicol 1993;72:128-33.

5. Lamb JC, Chapin RE, Teague J, Lawton AD, Reel JR. Reproductive effects of four phthalic acid esters in the mouse. Toxicol Appl Pharmacol 1987;88:255-69.

6. Parmar D, Srivastava SP, Singh GB, Seth PK. Testicular toxicity of di(2-ethylhexyl)phthalate in developing rats. Vet Hum Toxicol 1995;37:310-3.

7. Dostal LA, Chapin RE, Stefanski SA, Harris MW, Schwetz BA. Testicular toxicity and reduced Sertoli cell numbers in neonatal rats by di(2-ethylhexyl)phthalate and the recovery of fertility as adults. Toxicol Appl Pharmacol 1988;95:10421.

8. Agarwal DK, Eustis S, Lamb JC, Kluwe WM. Effects of 
di(2ethyl hexyl)phthalate on the gonodal patophysiology, sperm morphology, and reproductive performance of male rats. Environ Health Perspect 1986;65:343-50.

9. Arcadi FA, Costa C, Imperatore C, Marchese A, Rapisarda A, Salemi M, et al. Oral toxicity of bis(2-ethylhexyl) phthalate during pregnancy and suckling in the Long-Evans rat. Food Chem Toxicol 1998;36:963-70.

10. Poon R, Lecavalier,P, Mueller R, Valli VE, Procter BG, Chu I. Subchronic oral toxicity of di-n-octyl phthalate and di(2ethylhexyl) phthalate in the rat. Food Chem Toxicol 1997; 35:225-39.

11. Klimisch HJ, Gamer AO, Hellwig,J, Kaufmann W, Jackh R. Di-(2-ethylhexyl) phthalate: a short-term repeated inhalation toxicity study including fertility assessment. Food Chem Toxicol 1992;30:915-9.

12. Tanaka A, Adachi T, Takahashi T, Yamaha T. Biochemical studies on phthalic esters, I: elimination, distribution and metabolism of di-(2-ethylhexyl)phthalate in rats. Toxicology 1975;4:253-64.

13. Oishi S. Reversibility of testicular atrophy induced by di(2ethylhexyl) phthalate in rats. Environ Res 1985;36:160-9.

14. Working PK. Male reproductive toxicology: comparison of the human to animal models. Environ Health Perspect 1988;77:37-44.

15. Baird DD, Wilcox AJ, Weinberg CR. Use of time to pregnancy to study environmental exposures. Am J Epidemiol 1986;124:470-80.

16. Joffe M, Villard L, Li Z, Plowman R, Vessey M. A time to pregnancy questionnaire designed for long term recall: validity Oxford (England). J Epidemiol Community Health 1995; 49:314-9.

17. Joffe M. Time to pregnancy: a measure of reproductive function in either sex. Occup Environ Med 1997;54:289-95.

18. Cassinelli ME, O'Connor PF, editors. Manual of analytical methods (NMAM). 4th ed. Cincinnati $(\mathrm{OH})$ : National Institute for Occupational Health, 1994. NIOSH publication 44113.

19. Solomon HM, Burgess BA, Kennedy GL Jr, Staples RE. 1-methyl-2-pyrrolidone (NMP): reproductive and developmental toxicity study by inhalation in the rat. Drug Chem Toxicol 1995;18:271-93.

20. Weinberg CR, Wilcox AJ, Baird DD. Reduced fecundability in women with prenatal exposure to cigarette smoking. Am J Epidemiol 1989;129:1072-8.

21. Weinberg CR, Wilcox AJ. Reproductive epidemiology. In: Rothman KJ, Greenland S, editors. Modern epidemiology. New York (NY): Lippincott-Raven, 1998:585-608.

22. Wacholder, S. Binomial regression in GLIM: estimating risk ratios and risk differences. Am J Epidemiol 1986;124:63342.

23. Ahlborg G Jr, Axelsson G, Bodin L. Shift work, nitrous oxide exposure and subfertility among Swedish midwives. Int J Epidemiol 1996;25:783-90.

24. Bolumar F. Smoking reduces fecundity: a European multicenter study on infertility and subfecundity. Am J Epidemiol 1996;143:578-87.

25. Zielhuis GA, Hulscher ME, Florack EI. Validity and reliability of a questionnaire on fecundability. Int $\mathrm{J}$ Epidemiol 1992;21:1151-6.

26. Baird DD, Weinberg CR, Rowland AS. Reporting errors in time-to-pregnancy data collected with a short questionnaire: impact on power and estimation of fecundability ratios. Am J Epidemiol 1991;133:1282-90.

27. Coughlin MT, LaPorte RE, O'Leary LA, Lee PA. How accurate is male recall of reproductive information? Am J Epidemiol 1998;148:806-9.

28. Keiding N. Analysis of time-to-pregnancy data. Scand J Work Environ Health 1999;25 suppl 1:10-1.

29. Joffe M. Biases in research on reproduction and women's work. Int J Epidemiol 1985;14:118-23.

30. Högberg U, Sandström A, Nilsson NG. Reproductive patterns among Swedish women born 1936-1960. Acta Obstet Gynecol Scand 1992;71:207-14.

Received for publication: 7 November 2001 


\section{Appendix I}

Measurements of exposures to di(2-ethylhexyl)phthalate in the plants (I and II) processing polyvinyl chloride between 1982 and 1998.

\begin{tabular}{|c|c|c|c|c|c|c|}
\hline Task group & Location $^{a}$ & N & $\begin{array}{l}\text { Arithmetic mean } \\
\left(\mathrm{mg} / \mathrm{m}^{3}\right)\end{array}$ & $\begin{array}{l}\text { Geometric mean } \\
\left(\mathrm{mg} / \mathrm{m}^{3}\right)\end{array}$ & $\begin{array}{l}\text { Geometric } \\
\text { standard deviation }\end{array}$ & $\begin{array}{l}\text { Range } \\
\left(\mathrm{mg} / \mathrm{m}^{3}\right)\end{array}$ \\
\hline Machine attendants & Calender $3(\mathrm{I})$ & 19 & 0.49 & 0.41 & 1.86 & $0.22-0.77$ \\
\hline Rotation workers (1998) & Calender 3 (I) & 12 & 0.22 & 0.16 & 2.22 & $0.07-0.36$ \\
\hline Product controllers & Calender 3 (I) & 7 & 0.03 & 0.03 & 2.00 & $0.01-0.05$ \\
\hline Machine attendants & Calender 4 (I) & 14 & 0.17 & 0.14 & 1.95 & $0.07-0.27$ \\
\hline Product controllers & Calender 6 (I) & 7 & 0.29 & 0.27 & 1.43 & $0.19-0.39$ \\
\hline Machine attendants & Calender 8 (I) & 6 & 0.33 & 0.33 & 1.18 & $0.28-0.39$ \\
\hline Machine attendants & Calender 10 (I) & 18 & 0.41 & 0.37 & 1.64 & $0.23-0.61$ \\
\hline Calender operators & Calender 10 (I) & 4 & 0.67 & 0.63 & 1.42 & $0.45-0.90$ \\
\hline Product controllers & Calender 10 (I) & 7 & 0.17 & 0.16 & 1.37 & $0.12-0.22$ \\
\hline Machine attendants & Calender 20 (I) & 24 & 0.26 & 0.19 & 2.11 & $0.09-0.41$ \\
\hline Product controllers & Calender 20 (I) & 7 & 0.03 & 0.03 & 2.01 & $0.01-0.05$ \\
\hline Mixers & Calender 20 (I) & 4 & 0.13 & 0.11 & 1.87 & $0.06-0.21$ \\
\hline Machine attendants & Calender 2 (II) & 13 & 0.43 & 0.38 & 1.76 & $0.21-0.66$ \\
\hline Calender operators & Calender 2 (II) & 17 & 1.85 & 1.64 & 1.68 & $0.97-2.76$ \\
\hline Calender operators & Calender 4 (II) & 7 & 0.08 & 0.06 & 2.17 & $0.03-0.14$ \\
\hline Machine attendants & Calender 5 (II) & 18 & 0.04 & 0.02 & 2.74 & $0.01-0.07$ \\
\hline Machine attendants & Calender 6 (II) & 3 & 0.28 & 0.28 & 1.04 & $0.27-0.29$ \\
\hline Calender operators & Calender 6 (II) & 7 & 0.52 & 0.47 & 1.59 & $0.29-0.74$ \\
\hline Machine attendants & Calender 7 (II) & 17 & 0.10 & 0.08 & 2.55 & $0.03-0.19$ \\
\hline Calender operators & Calender 7 (II) & 10 & 0.36 & 0.12 & 4.91 & $0.02-0.60$ \\
\hline
\end{tabular}

a Plant delineated by Roman number in parentheses.

\section{Appendix II}

One-way analysis of variance to test for differences in exposure to di(2-ethylhexyl)phthalate between measurements in different years.

\begin{tabular}{llllcc}
\hline Task group & Location a & Years of measurement & Mean values $\left(\mathrm{mg} / \mathrm{m}^{3}\right)$ & $\mathrm{F} \sigma_{\text {bw }}^{2} / \sigma_{\text {years }}^{2}$ & Probability \\
\hline Machine attendants & Calender 3 (I) & $1984,1996,1997$ & $0.39,0.40,0.69$ & 2.81 & 0.09 \\
Machine attendants & Calender 10 (I) & $1982,1996,1998$ & $0.28,0,48,0.47$ & 3.48 & 0.06 \\
Product controllers & Calender 10 (I) & 1996,1998 & $0.15,0.18$ & 0.45 & 0.53 \\
Machine attendants & Calender 20 (I) & $1984,1996,1997,1998$ & $0.19,0.12,0.28,0.39$ & 1,37 & 0.28 \\
Machine attendants & Calender 2 (II) & $1982,1984,1986$ & $0.20,0.40,0.57$ & 3.58 & 0.07 \\
Machine attendants & Calender 7 (II) & $1982,1984,1986,1998$ & $0.10,0.07,0.07,0.23$ & 3.86 & 0.04 \\
Calender operators & Calender 7 (II) & $1984,1986,1988$ & $0.82,0.12,0.39$ & 1.32 & 0.33 \\
\hline
\end{tabular}

a Plant delineated by Roman number in parentheses. 